Western North American Naturalist 68(2), (C) 2008, pp. 225-230

\title{
IMPLICATIONS OF POLYPLOIDY IN THE HOST PLANT OF A DIPTERAN SEED PARASITE
}

\author{
Rebecca Hufft Kao ${ }^{1,2}$
}

\begin{abstract}
Although polyploidy can alter host plants in important ways (e.g., size, phenology, resource use, and ecological range), little is known about the effects of polyploidy-associated changes on plant-insect interactions. The presence of Campiglossa footeorum Novak (Diptera: Tephritidae) and its effect on its host plant Arnica cordifolia Hook. (Asteraceae) were monitored throughout Colorado, where triploids and tetraploids of the host plant occur. Campiglossa footeorum is more abundant in sites with more tetraploids and attacks tetraploids more than triploids. Polyploidy could be an important force shaping the current evolutionary trajectory of the plants and insects in this system. Campiglossa footeorum is intimately linked to A. cordifolia, and polyploidy should be included in any assessment of the insect's population dynamics.
\end{abstract}

Key words: polyploidy, Campiglossa footeorum, Tephritidae, Arnica cordifolia, seedhead gall former, plant-insect interactions.

A large proportion of angiosperms are polyploids (Grant 1981, Masterson 1994), having doubling (or higher multiplication) of chromosomes. Polyploidy is thought to be important in shaping plant-insect interactions and possibly even terrestrial diversity (Thompson et al. 2004). However, despite its ubiquity, there have been few studies on the effects of polyploidy on interactions between plants and animals. Polyploidy in the host plant has been shown to affect insect pollinators, seed parasites, herbivores, and root miners (Muller 1989, Thompson et al. 1997, Nuismer and Thompson 2001, Janz and Thompson 2002, Lou and Baldwin 2003). It can also lead to changes in morphology and phenology (Stebbins 1971, Levin 1983, Otto and Whitton 2000), differential habitat and resource use, and an increase in the ecological range of a species (Brochmann and Elven 1992, Felber-Girard et al. 1996, Gauthier et al. 1998, Petit and Thompson 1999), all of which could affect plant-insect interactions.

The few studies that have compared cytotypes have all found evidence for differentiation in host use between ploidy levels (Thompson et al. 1997, 2004, Segraves and Thompson 1999, Husband and Schemske 2000, Nuismer and Thompson 2001), suggesting that differences resulting from polyploidy could be important to the ecology and evolution of the insects utilizing the host plants. Although insects appear to be able to differentiate between ploidy levels, the level of impact and even direction of effect differ among species. Some insects preferentially attack tetraploids over diploids (Thompson et al. 1997, Janz and Thompson 2002); others show higher attack rates on diploids than tetraploids (Lou and Baldwin 2003). Because we still have very few examples to draw on, no generalizations can be made to explain these differences in preference despite the likely important role of polyploidy in generating variation in host choice.

Arnica cordifolia Hook. (Asteraceae) is a mature polyploid complex containing diploids, triploids, tetraploids, and pentaploids (Ornduff et al. 1963, 1967, Wolf 1980, 1987, Kao 2007, 2008). Triploids and tetraploids occur sympatrically and both appear to be pseudogamous apomicts (producing asexual seeds; Kao 2007). The tetraploids are larger with bigger leaves, fewer stomata, and fewer flowers per inflorescence (Kao 2006, 2007). Such morphological changes provide the opportunity for differential detection and attack by insects. I investigated the effects of a Dipteran seedhead gall former, Campiglossa footeorum Novak (Diptera: Tephritidae), on sympatric triploids and tetraploids of A. cordifolia in Colorado. The influences of ploidy on attack rate at both the individual and the population level were

${ }^{1}$ Ecology and Evolutionary Biology, University of California Santa Cruz, 1156 High St., Santa Cruz, CA 95064.

${ }^{2}$ Present address: NEON, Inc., 3223 Arapahoe Ave., Boulder, CO 80303. E-mail: bkao@neoninc.org 
TABLE 1. Descriptive data for collection sites, proportion of tetraploids, fly attack rate, and number of individual plants sampled.

\begin{tabular}{|c|c|c|c|c|c|c|}
\hline Site & Elevation (m) & Latitude $(\mathrm{N})$ & Longitude $(W)$ & Tetraploid $(\%)$ & Fly attack $(\%)$ & Plants sampled \\
\hline 1 Buffalo Peaks & 3171 & $39^{\circ} 01.680^{\prime}$ & $106^{\circ} 04.640^{\prime}$ & 33 & 6.0 & 215 \\
\hline 2 Fraser & 2752 & $39^{\circ} 55.241^{\prime}$ & $105^{\circ} 50.128^{\prime}$ & 44 & 32.2 & 152 \\
\hline 3 Hoosier Pass & 3517 & $39^{\circ} 21.735^{\prime}$ & $106^{\circ} 03.708^{\prime}$ & 0 & 20.7 & 92 \\
\hline 4 McGullough Gulch & 3395 & $39^{\circ} 23.578^{\prime}$ & $106^{\circ} 03.528^{\prime}$ & 85 & 45.2 & 31 \\
\hline 5 McGullough Gulch OS & 3200 & $39^{\circ} 24.134^{\prime}$ & $106^{\circ} 03.079^{\prime}$ & 17 & 50.0 & 20 \\
\hline 6 Michigan Hill & 3137 & $39^{\circ} 25.226^{\prime}$ & $105^{\circ} 52.892^{\prime}$ & 71 & 40.8 & 103 \\
\hline 7 Monarch Pass Campground & ad 3171 & $38^{\circ} 31.667^{\prime}$ & $106^{\circ} 19.524^{\prime}$ & 100 & 54.0 & 50 \\
\hline 8 Beaver Meadows & 2859 & $40^{\circ} 23.735^{\prime}$ & $105^{\circ} 39.105^{\prime}$ & 44 & 60.8 & 51 \\
\hline 9 Coyote Trail & 2710 & $40^{\circ} 20.714^{\prime}$ & $105^{\circ} 51.497^{\prime}$ & 0 & 5.3 & 19 \\
\hline 10 Green Mountain Trail & 2696 & $40^{\circ} 18.444^{\prime}$ & $105^{\circ} 50.477^{\prime}$ & 75 & 55.1 & 48 \\
\hline 11 Onahu Trail & 2680 & $40^{\circ} 17.116^{\prime}$ & $105^{\circ} 50.277^{\prime}$ & 7 & 33.3 & 18 \\
\hline 12 Weminuche & 3326 & $37^{\circ} 42.470^{\prime}$ & $107^{\circ} 24.689^{\prime}$ & 100 & 40.0 & 5 \\
\hline TOTAL & & & & & & 804 \\
\hline
\end{tabular}

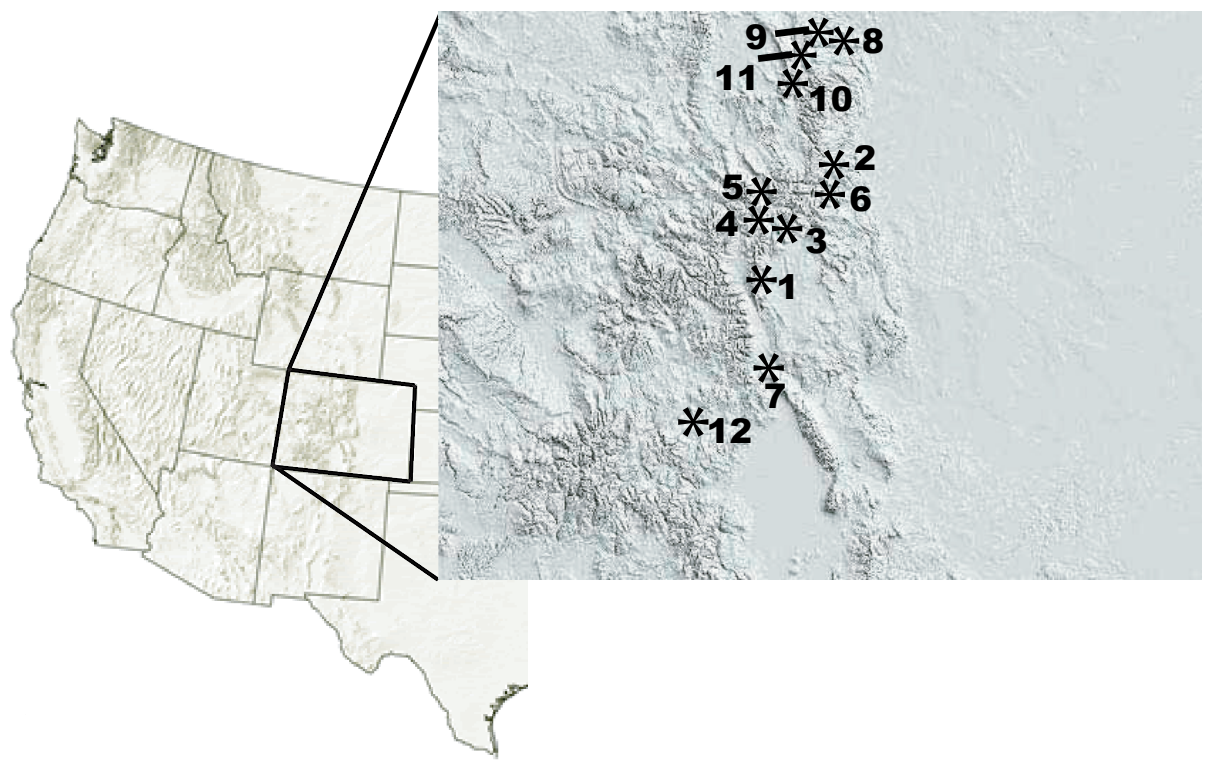

Fig. 1. Colorado collection sites, with stars showing location of site and numbers indicating site name (see Table 1).

explored. This is the 1st study of this parasite on its host in the field and the 1st work to investigate the implications of changes associated with polyploidy in this plant-insect interaction.

\section{Methods}

Arnica cordifolia is a rhizomatous perennial with yellow ray and disk flowers arranged in a composite inflorescence. Largely a woodland plant (Maguire 1943), Arnica cordifolia can be found in high meadows and coniferous forests at 1200-3000 m (Hickman 1996), ranging from
Alaska to New Mexico and California (Maguire 1943). In Colorado many sites support populations of both tetraploid and triploid individuals (Kao 2007, 2008).

I collected as many inflorescences of $A$. cordifolia as could be found at 14 sites in Colorado (Table 1, Fig. 1). For plants with more than 1 inflorescence (7\%), all inflorescences were collected. There was no difference in the number of inflorescences between ploidies (Kao 2007). For seed and pupal case data, inflorescences were collected when mature. For fly identification, I collected inflorescences while they were still in bud and green and 

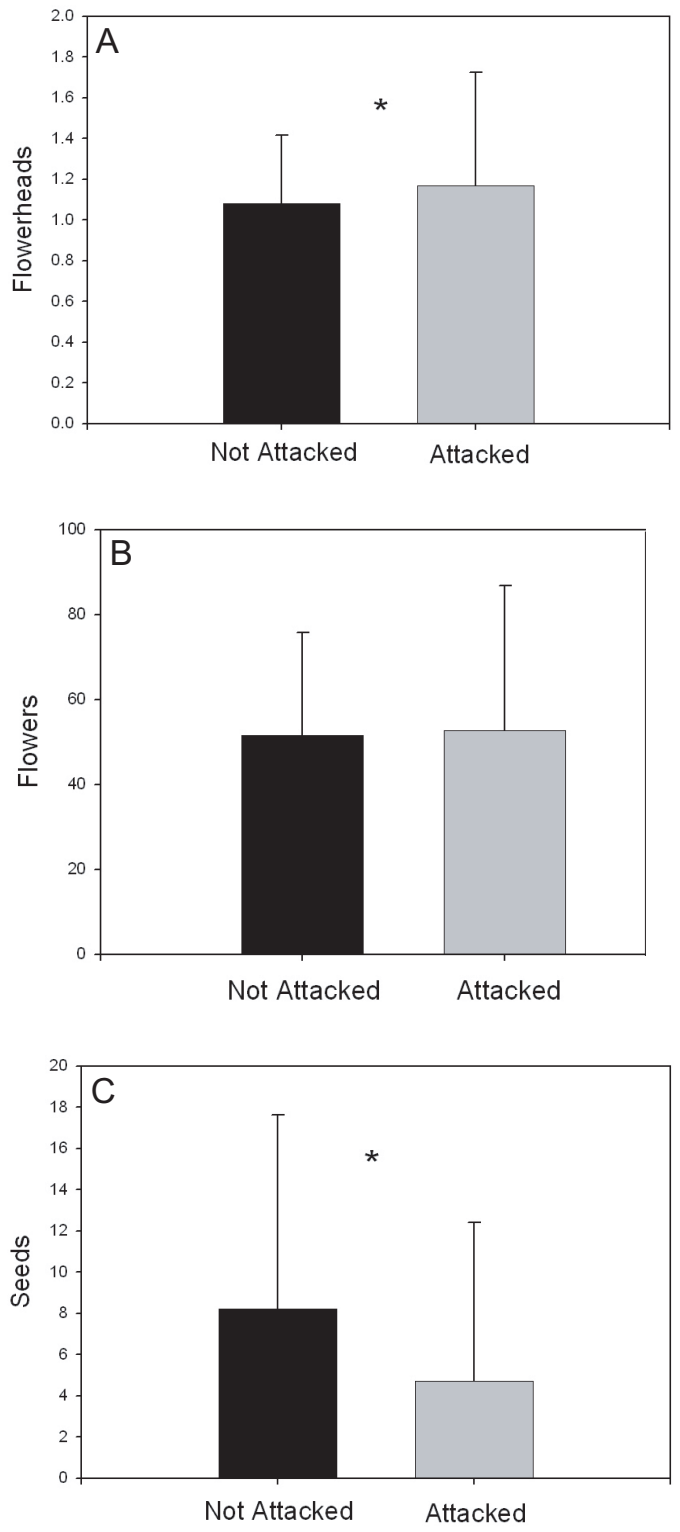

Fig. 2. The average number of inflorescences (A), flowers (B), and seeds (C) produced per plant for plants attacked and not attacked by flies. Bars represent 1 standard deviation. An asterisk indicates that $P<0.05$.

kept them in bags until flies emerged. Seven reference specimens were pinned and sent to the USDA entomology laboratory in Beltsville, Maryland, where they were identified by Allen Norrbom as Campiglossa footeorum and Euarestoides acutangulus Thomson. All specimens caught in the inflorescence (either dead in the pupal case or just after eclosing) were verified

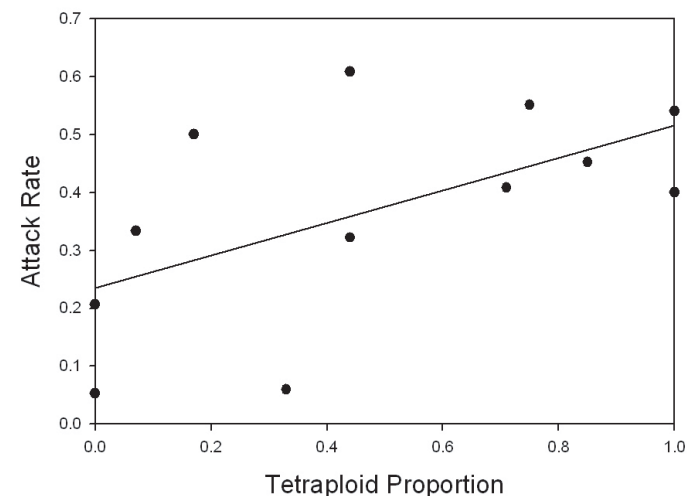

Fig. 3. The proportion of plants at sites attacked by flies relative to the proportion of tetraploids in that site, shown with the linear regression line.

as C. footeorum, except in 1 inflorescence, which was attacked by E. acutangulus. Campiglossa footeorum is known from 15 specimens from British Colombia to Wyoming and has been found only on Arnica (http://www.sel.barc .usda.gov:591/diptera/tephritidae/TephIntro . $\mathrm{html}$ ). Euarestoides acutangulus is a generalist previously found on 8 genera (Foote et al. 1993).

The number of inflorescences per plant was recorded. For all inflorescences collected, I counted the number of achenes, developed seeds, and fly pupal cases. All flowers produce a single fruit, the achene, regardless of seed set. Most pupal cases were empty (the flies had already eclosed), but many still contained mature fly pupae with visible wing patterns. For analyses, the number of flies per inflorescence refers to the number of pupal cases found. The numbers of inflorescences, flowers, and seeds per plant were compared between plants that were attacked and those that were not attacked using an ANOVA with site as a blocking factor. Linear regression was used to describe the relationship between the number of flies and seed set per plant. All statistical analyses were performed using Systat v 10.2 (Systat Software, Inc. 2002, http://www.systat .com). The numbers of flies, flowers, and seeds per plant were $\log _{e}($ data +1$)$ transformed to increase homogeneity of variances.

Using fresh leaf material collected from 5-218 individuals per site (Kao 2007, 2008), I determined the proportion of triploids and tetraploids at each site. To compare attack rates for triploids and tetraploids, I analyzed samples with seeds with flow cytometry to 

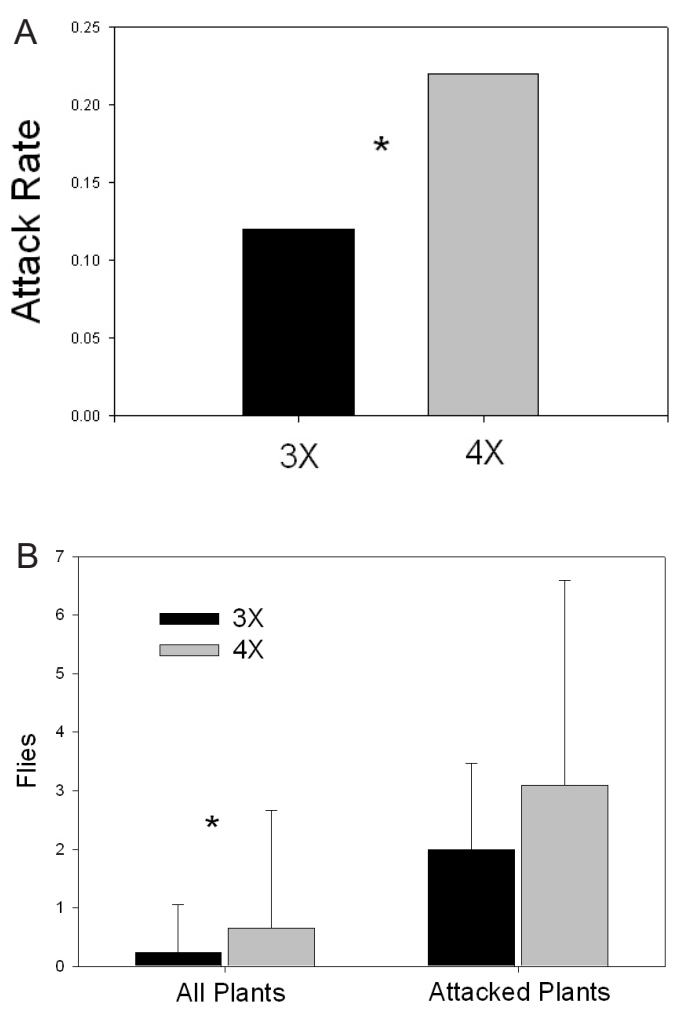

Fig. 4. The attack rate per ploidy (A), and the number of flies per individual for all plants and only those attacked (B). Bars represent 1 standard deviation. An asterisk indicates that $P<0.05$.

determine seed ploidy level following the methods of Arumuganathan and Earle (1991, Kao 2007), and the ploidy of the mother plant was inferred from the ploidy of the asexual seed. Samples without seeds could not be cytotyped, because achenes alone do not provide ploidy information with this method. A $t$ test compared the number of flies per plant between triploids and tetraploids, and the relationship between fly attack rate at the population level and the proportion of triploids was tested using linear regression. Only those sites with at least 15 individuals were used in this last analysis.

\section{RESUlTS}

The flies arrived early in flower development and parasitized the central flowers in the inflorescence. The flowers they use do not develop properly, but rather are short, fat, and fused together to form a case around the pupal cases.
If the inflorescence is large enough, flowers develop normally around the outer edge. Often, a visible hole is chewed through the achene, presumably eaten by fly larvae. Adult flies emerged from 13 July to 14 August at 9 sites.

Attack rates ranged from 5\%-61\% (Table 1). Although only a small proportion of plants had $>1$ composite inflorescence, attacked plants had more inflorescences than unattacked plants $\left(F_{1,791}=5.55, P=0.019\right.$; Fig. $\left.2 \mathrm{~A}\right)$. There was no difference in the number of flowers per plant between those attacked by flies and those not attacked $\left(F_{1,753}=1.74, P\right.$ $=0.19$; Fig. 2B). Attacked plants had significantly fewer seeds than those not attacked $\left(F_{1,791}=34.55, P<0.001\right.$; Fig. 2 C). Seed set decreased with the number of flies per plant $\left(F_{1,802}=30.66, P<0.001, R^{2}=0.036\right)$. Sites with a higher frequency of tetraploids had higher rates of fly attack $\left(F_{1,10}=4.92, P=\right.$ $0.05, R^{2}=0.26$; Fig. 3). At the individual level, tetraploids were also attacked marginally significantly more often than triploids $(n$ $=215, \chi^{2}{ }_{1}=3.71, P=0.054$; Fig. $4 \mathrm{~A}$ ). Of all the plants for which set seed and ploidy could be measured, both attacked and not attacked, tetraploids had more flies than triploids $\left(t_{213}\right.$ $=2.26, P=0.025$; Fig. 4B). However, if only the attacked plants are considered, there was no difference in the number of flies between triploids and tetraploids $\left(t_{33}=1.20, P=\right.$ 0.236; Fig. 4B).

\section{Discussion}

The data presented here are the 1st collections of Campiglossa footeorum known from Colorado, suggesting that the flies are ubiquitous on Arnica cordifolia throughout Colorado. Campiglossa footeorum appears to be the usual and most common seed predator of A. cordifolia, which is also rarely attacked by Euarestoides acutangulus. These data are the first from any field study about C. footeorum, its association with host ploidy, and its effect on its host. Campiglossa footeorum is more common in populations with more tetraploids of A. cordifolia and attacks tetraploids more than triploids.

The host plant likely has a great effect on the insect's survival and evolution because much of its reproduction is directly associated with its host plant. Only 4\%-6\% of individuals of A. cordifolia flower every year (Kao 2007), 
making host choice and timing difficult for the seedhead gall formers since they must lay eggs prior to floral development but late enough to ensure that the host will actually flower. It is not clear why $C$. footeorum attacks tetraploids more than triploids. Though there is some overlap, triploids flower earlier than tetraploids (Kao 2007), so timing could affect fly attack. Additionally, as mentioned above, there are morphological differences between cytotypes (such as size and flower number; Kao 2007), which could be important in host selection.

Attacked host plants have fewer seeds than unattacked plants. The differential attack between triploid and tetraploid host plants could govern the frequency of each ploidy within a population. The combination of flower destruction and seed consumption by the fly is not necessarily detrimental to population dynamics of the host since the plants are perennial and can spread vegetatively via rhizomes. However, given that seed production is rare and high seed mortality occurs when flies attack, this interaction is potentially important to the long-term fecundity of individuals and evolution of the host species.

Insects and their host plants can be strong selective forces on each other. For example, an increase in flowers can lead to an increase in seed predation (Brody and Mitchell 1997, Leimu et al. 2002), and seed predation, in turn, can be a strong selective agent on floral traits (Cariveau et al. 2004). In addition, polyploidization can have large effects on other plant morphological and physiological traits that could be important in host selection (Janz and Thompson 2002). Despite the important ecological and evolutionary relationships between insects and their host plants, we still know very little about the effects of host polyploidy on insect host selection or attack rates. As this work shows, host polyploidy can strongly influence insect distribution and abundance. Although C. footeorum occurs in every A. cordifolia study site regardless of ploidy abundance, more flies are found in sites with more tetraploids. At the individual level, flies attack tetraploids more. Polyploidy could be an important force shaping the current evolutionary trajectory of the plants and insects in this system. Campiglossa footeorum is intimately linked to A. cordifolia and polyploidy should be included in any assessment of the insect's population dynamics.

\section{ACKNOWLEDGMENTS}

Funding for this research was provided by an NSF DDIG (DEB-0508633) to RHK. Fly identification was provided by Allen L. Norrbom, Systematic Entomology Laboratory, Agriculture Research Service, U.S. Department of Agriculture. Thanks go to Courtney Angelo for lab assistance and to Ingrid Parker, Grant Pogson, and Gregory Gilbert for help with formulating ideas and revising the manuscript.

\section{Literature Cited}

Arumuganathan, K., And E.D. EArLe. 1991. Estimation of nuclear DNA content of plants by flow cytometry. Plant Molecular Biology 9:229-233.

Brochmann, C., and R. Elven. 1992. Ecological and genetic consequences of polyploidy in arctic Draba (Brassicaceae). Evolutionary Trends in Plants 6:111124.

Brody, A.K., And R.J. Mitchell. 1997. Effects of experimental manipulation of inflorescence size on pollination and pre-dispersal seed predation in the hummingbird-pollinated plant Ipomopsis aggregata. Oecologia 110:86-93.

Cariveau, D., R.E. Irwin, A.K. Brody, L.S. GarciaMayeya, AND A. von Der OHE. 2004. Direct and indirect effects of pollinators and seed predators to selection on plant and floral traits. Oikos 104:15-26.

Felber-Girard, M., F. Felber, and A. Buttler. 1996. Habitat differentiation in a narrow hybrid zone between diploid and tetraploid Anthoxanthum alpinum. New Phytologist 133:531-540.

Foote, R., F. Blanc, and A. Norrbom. 1993. Handbook of the fruit flies (Diptera: Tephritidae) of America North of Mexico. Comstock Publishing Association, Ithaca, NY.

Gauthier, P., R. Lumaret, and A. Bedecarrats. 1998. Genetic variation and gene flow in alpine diploid and tetraploid populations of Lotus (L. alpinus (D.C.) Schleicher/L. corniculatus L.). I. Insights from morphological and allozyme markers. Heredity 80:683693.

Grant, V. 1981. Plant speciation. Columbia University Press, New York.

Hickman, J.C. 1996. The Jepson manual: higher plants of California. University of California Press, Berkeley.

Husband, B.C., AND D.W. Schemske. 2000. Ecological mechanisms of reproductive isolation between diploid and tetraploid Chamerion angustifolium. Journal of Ecology 88:689-701.

JAnZ, N., AND J.N. ThOmpson. 2002. Plant polyploidy and host expansion in an insect herbivore. Oecologia (Berlin) 130:570-575.

KaO, R.H. 2006. The coexistence of polyploids in Arnica cordifolia (Asteraceae). Doctoral dissertation, University of California, Santa Cruz.

2007. Asexuality and the coexistence of cytotypes. New Phytologist 174:764-772.

. 2008. Origins and widespread distribution of coexisting polyploids in Arnica cordifolia (Asteraceae). Annals of Botany 101:145-152. 
Leimu, R., K. Syrjanen, J. Ehrlen, and K. Lehtila. 2002. Pre-dispersal seed predation in Primula veris: amongpopulation variation in damage intensity and selection on flower number. Oecologia 133:510-516.

LEvin, D.A. 1983. Polyploidy and novelty in flowering plants. American Naturalist 122:1-25.

LOU, Y., AND I.T. BALDWIN. 2003. Manduca sexta recognition and resistance among allopolyploid Nicotiana host plants. Proceedings of the National Academy of Sciences of the United States of America 100:1458114586.

Maguire, B. 1943. A monograph of the genus Arnica. Brittonia 4:386-510.

Masterson, J. 1994. Stomatal size in fossil plants: evidence for polyploidy in majority of angiosperms. Science 264:421-424.

MulleR, H. 1989. Growth-pattern of diploid and tetraploid spotted knapweed, Centaurea maculosa Lam (Compositae), and effects of the root-mining moth Agapeta zoegana (L.) (Lep, Cochylidae). Weed Research 29:103.

Nuismer, S.L., AND J.N. ThOmPSON. 2001. Plant polyploidy and non-uniform effects on insect herbivores. Proceedings of the Royal Society Biological Sciences Series B 268:1937-1940.

Ornduff, R., T. Mosquin, D.W. Kyhos, and P.H. Raven. 1967. Chromosome numbers in Compositae. VI. Senecioneae. II. American Journal of Botany 54:205213

Ornduff, R., P.H. Raven, D.W. Kyhos, and A.R. KruckEBERG. 1963. Chromosome numbers in Compositae.
III. Senecioneae. American Journal of Botany 50: 131-139.

OtTo, S.P., And J. WhitTon. 2000. Polyploid incidence and evolution. Annual Review of Genetics 34:401-437.

Petit, C., AND J.D. Thompson. 1999. Species diversity and ecological range in relation to ploidy level in the flora of the Pyrenees. Evolutionary Ecology 13:45-66.

Segraves, K.A., And J.N. Thompson. 1999. Plant polyploidy and pollination: floral traits and insect visits to diploid and tetraploid Heuchera grossulariifolia. Evolution 53:1114-1127.

Stebbins, G.L. 1971. Chromosomal evolution in higher plants. Addison-Wesley Publishing Company, London.

Thompson, J.N., B.M. Cunningham, K.A. Segraves, D.M. Althoff, And D. Wagner. 1997. Plant polyploidy and insect/plant interactions. American Naturalist 150:730-743.

Thompson, J.N., S.L. Nuismer, And K. Merg. 2004. Plant polyploidy and the evolutionary ecology of plant/animal interactions. Biological Journal of the Linnean Society 82:511-519.

WoLF, S. 1987. Cytotaxonomic studies in the genus Arnica (Compositae:Senecioneae). Rhodora 89:391-400.

WoLF, S.J. 1980. Cytogeographical studies in the genus Arnica (Compositae: Senecioneae). I. American Journal of Botany 67:300-308.

Received 14 May 2007 Accepted 26 November 2007 